\title{
Article \\ Systematic Mapping of Long-Term Urban Challenges
}

\author{
Ralf-Martin Soe ${ }^{1}\left(\mathbb{D}\right.$, Lill Sarv $^{1, *(\mathbb{D})}$ and Mila Gasco-Hernandez ${ }^{2}$ (D) \\ 1 FinEst Centre for Smart Cities, Tallinn University of Technology, 19086 Tallinn, Estonia; \\ ralf-martin.soe@taltech.ee \\ 2 Center for Technology in Government, University at Albany, SUNY 1400 Washington Avenue, UAB 120, \\ Albany, NY 12222, USA; mgasco@albany.edu \\ * Correspondence: lill.sarv@taltech.ee
}

Citation: Soe, R.-M.; Sarv, L.; Gasco-Hernandez, M. Systematic

Mapping of Long-Term Urban Challenges. Sustainability 2022, 14, 817. https://doi.org/10.3390/ su14020817

Academic Editor: Wann-Ming Wey

Received: 15 December 2021

Accepted: 9 January 2022

Published: 12 January 2022

Publisher's Note: MDPI stays neutral with regard to jurisdictional claims in published maps and institutional affiliations.

Copyright: (C) 2022 by the authors. Licensee MDPI, Basel, Switzerland This article is an open access article distributed under the terms and conditions of the Creative Commons Attribution (CC BY) license (https:// creativecommons.org/licenses/by/ $4.0 /)$.

\begin{abstract}
This paper investigates on long-term challenges faced by local governments. Using empirical evidence from Estonia, this paper aims to help fill a research gap in that there is a lack of a systematic approach on how to analyze common urban challenges via direct involvement of local governments. In terms of conceptual framework, a unique combination of public value theory and mission-oriented innovation is proposed. The data is collected via questionnaire, interviews and workshops involving up to 35 local governments. It is important that instead of current problems relating only to one city, this study focuses on finding shared, long-term challenges and, from them, generates a list of top 10 challenges. This provides valuable input to initiating new research and innovation projects in the key, smart city domains (e.g., energy, mobility, built environment, governance and data).
\end{abstract}

Keywords: sustainable urban development; smart city; urban challenges; public value; missionoriented innovation

\section{Introduction}

Although smart city, as a concept, lacks theoretical precision [1-3], it has become a popular term to describe cities that [4]:

- Adopt a global/integral view of the city, which materializes in different types of initiatives, from waste management to traffic control to water management.

- Integrate a double perspective, technological and human. Technology is key in the development of smart cities (and, therefore, it is the tool par excellence); however, smart cities have to be developed for, by, and with citizens. As a result, urban governance and participation processes, as well as investments in human and social capital, are inherent attributes of a smart city.

- Pursue a triple goal: (1) to improve the efficiency of urban operations, (2) to improve citizen quality of life, and (3) to promote the local economy, while maintaining environmental sustainability.

Instrumentally, smart cities have emerged to address the challenges driven by exponential growth of urbanisation $[5,6]$, such as dealing with the problems associated with a growing urban population, which may include social, economic and environmental issues [7], reducing the amount of energy and resources consumed under the pressure of continuously increasing standards of living, and competing with other cities for companies, tourists and, most of all, talents [8,9].

Although most research literature on smart cities [4,10-12] as well as a broad range of non-academic reports (e.g., the Smart City Challenge report by the US Department of Transportation; Smart Cities and Inclusive Growth, by the OECD, and Smart cities: Digital solutions for a more livable future, by McKinsey Global Institute) have acknowledged the role of smart cities in addressing current urban challenges; diagnostic approaches to the identification of urban challenges that smart city initiatives may address are surprisingly 
rare [13]. Yet, this is an important issue because, although it may seem that cities share similar challenges, the importance of context in shaping urban problems [14] reveals that cities do not share the same problems, to the same degrees or in the same combinations. A better understanding of urban challenges may also result in the design of more targeted smart city initiatives and, therefore, higher chances for smart cities to fulfil their ultimate goals: creating public value and improving the quality of life of their citizens.

Our study aims to partially fill this gap by proposing a transferable and participatory roadmap for systematically identifying, defining, and understanding urban challenges. We test this approach in 35 local governments in Estonia. The accompanying research questions of our study are: (1) What are the current approaches to identify and define urban challenges and what advantages and disadvantages do they have? (2) What are the underlying principles that an urban challenge diagnostic tool should take into account? (3) What are the benefits and the challenges of the use of the proposed roadmap for both researchers and experts? This study applied a qualitative research method via data gathering and analysis of 35 local governments in Estonia as a case. The data was collected via survey (16 municipalities participated), interviews (16 municipalities participated) and ranking workshops (29 municipalities participated).

The remainder of this article is organized as follows: In the following section, we present the literature on urban challenges and current methodologies to identify and understand them. Next, we develop our roadmap. We start presenting the underlying principles that frame the approach to continue with an explanation of its specific development. Subsequently, we describe an application in 35 municipalities in Estonia and assess its results, benefits, and challenges. Finally, we draw conclusions of the findings from the Estonian case, putting them in the context of the literature.

\section{Mapping Long-Term Urban Challenges}

Although there is extensive literature on the topic of urbanness and therefore on the many dimensions that characterize an urban area [15], there does not seem to be a standard definition of what an urban area is. According to a publication by the United Nations DESA (https://www.un.org/en/development/desa/population/events/pdf/ expert/27/papers/II/paper-Moreno-final.pdf, accessed on 14 December 2021), different countries have their own definitions and collect data accordingly, usually considering population size, population density, type of economic activity, physical characteristics, level of infrastructure, or a combination of these or other criteria. For example, the US Census Bureau identifies as urban any incorporated place or census-designated place of at least 2500 (https:/ / www.federalregister.gov/documents/2021/02/19/2021-03412/urbanareas-for-the-2020-census-proposed-criteria, accessed on 14 December 2021). It actually distinguishes two types of urban areas: urbanized areas of 50,000 or more people, and urban clusters of at least 2500 and less than 50,000 people, both representing densely developed territory and encompassing residential, commercial, and other non-residential urban land uses. In contrast, Germany and China use minimum population density thresholds, 150 persons per square kilometer for the first country and 1500 for the second, according to the World Bank (https://blogs.worldbank.org/sustainablecities/what-does-urban-mean, accessed on 14 December 2021).

The lack of academic and practical consensus of what "urban" means has important implications because it makes it difficult to identify and characterize urbanization processes and therefore to well understand their associated challenges. That is why, in this study, we follow Weeks' [15] proposal and define an urban area as a "spatial concentration of people whose lives are organized around nonagricultural activities." Weeks [15] states that "the urbanness of a place is determined based on a range of elements encompassing population size and density, social and economic organization, and the transformation of the natural and agricultural environments into a built environment." Metropolitan areas, cities, towns, conurbations, and suburbs are some types of urban areas as classified by urban morphology [16]. 
Both the literatures on urbanization and on smart cities have acknowledged the challenges associated to urban areas, such as land-use regulation, urban maintenance, natural resource sustainability, and production and management of services, such as water supply, education, safety, or transportation. As urban areas grow, these problems become more tangled and wicked, often resulting in the adoption of smart city approaches by urban governments to address them [14]. Interestingly enough, these smart city solutions or initiatives are costly to implement, given the technology involved. This is why, among other reasons, it is key to accurately identify what the critical urban problems are for a specific urban area.

In general, other than relying on pre-defined urban challenges, there seems to be no standardized process to identify the critical problems of individual urban areas. Rather, different cities have different motivations and follow different approaches to do so. In this respect, Leach et al. [13] state: "problem identification may be politically or socially motivated, may focus on well-known or fashionable challenges, or may follow funding availability" (p. 136). Similarly, the literature on urban challenges has mirrored the absence of diagnostic tools and has focused on the urban problems themselves. In one of the few reviews of the literature on urban challenge diagnostics, Leach et al. [13] present four types of studies to identify and understand urban problems: (1) studies that describe, investigate, and measure urban challenges; (2) studies that focus upon how to best identify and/or address a challenge or set of challenges, either methodologically or via specific interventions; (3) studies that assess the efficacy of programs, policies, and technologies designed to address urban challenges; and (4) studies that focus upon urban characterizations and ethnographies. Yet, the authors acknowledge that there are almost no studies where urban challenges of a single city are systematically diagnosed in an open process.

With the aims of expanding the review by Leach et al. [13] of the literature and of having a more accurate picture of current studies on urban challenge diagnoses, on 24 May 2021, we searched articles included in two main bibliographic online databases, Scopus and Web of Science, between 2018-2021, using a single keyword "urban challenges" within the title, abstract, and keywords. We found 196 papers in Scopus and 136 in the Web of Science, altogether 332 articles. These papers were all published in English and they represented mainly the following subject areas: Social Sciences, Environmental Science, Engineering and Computer Science. The removal of duplicates resulted in a final number of 194 articles (see Figure 1). Based on the title, abstract and keywords, we eliminated the ones that had presumably nothing to do with identifying urban challenges and we read through the abstracts of 71 articles, including the full-text of these if the abstracts were not clear enough.

Sixty-four papers that we screened, and then excluded from the detailed analysis, tended to focus on one specific pre-defined field of study without an attempt to apply an open approach to identify more contextual and horizontal urban challenges. For example, there were several papers somehow linked to urban challenges but with an actual focus area somewhere else (e.g., food security, automated driving, gig economy, digital twin, risk governance, disaster management, water systems, mental health, forestry, built environment, mobility apps, public procurement, sensor-based-parking, security infrastructure, rental market, living labs, etc.).

This screening eventually led to the inclusion of seven publications: [11,13,17-21]. For each publication, we analyzed the methods used to identify urban challenges. According to this sample of literature, we already introduced, above, the most relevant method for diagnosing urban challenges in one city in Leach et al. [13]. The two most cited papers $[11,18]$ focused on universal "one-size-fits-all" urban challenges, mainly based on previous literature or predefined global trends (climate change, ageing, urbanization). In the case of Fernandez-Anez et al. [11], "one-size-fits-all" urban challenges were validated during interviews with the stakeholders and accordingly modified, which was also the case in the rest of the papers.

Next, van Winden \& Carvalho [20] studied how start-up companies can solve urban challenges in the city of Amsterdam, however, there is no systematic description of how 
these urban challenges were agreed upon, it is only stated that "once defined, urban challenges were published online".

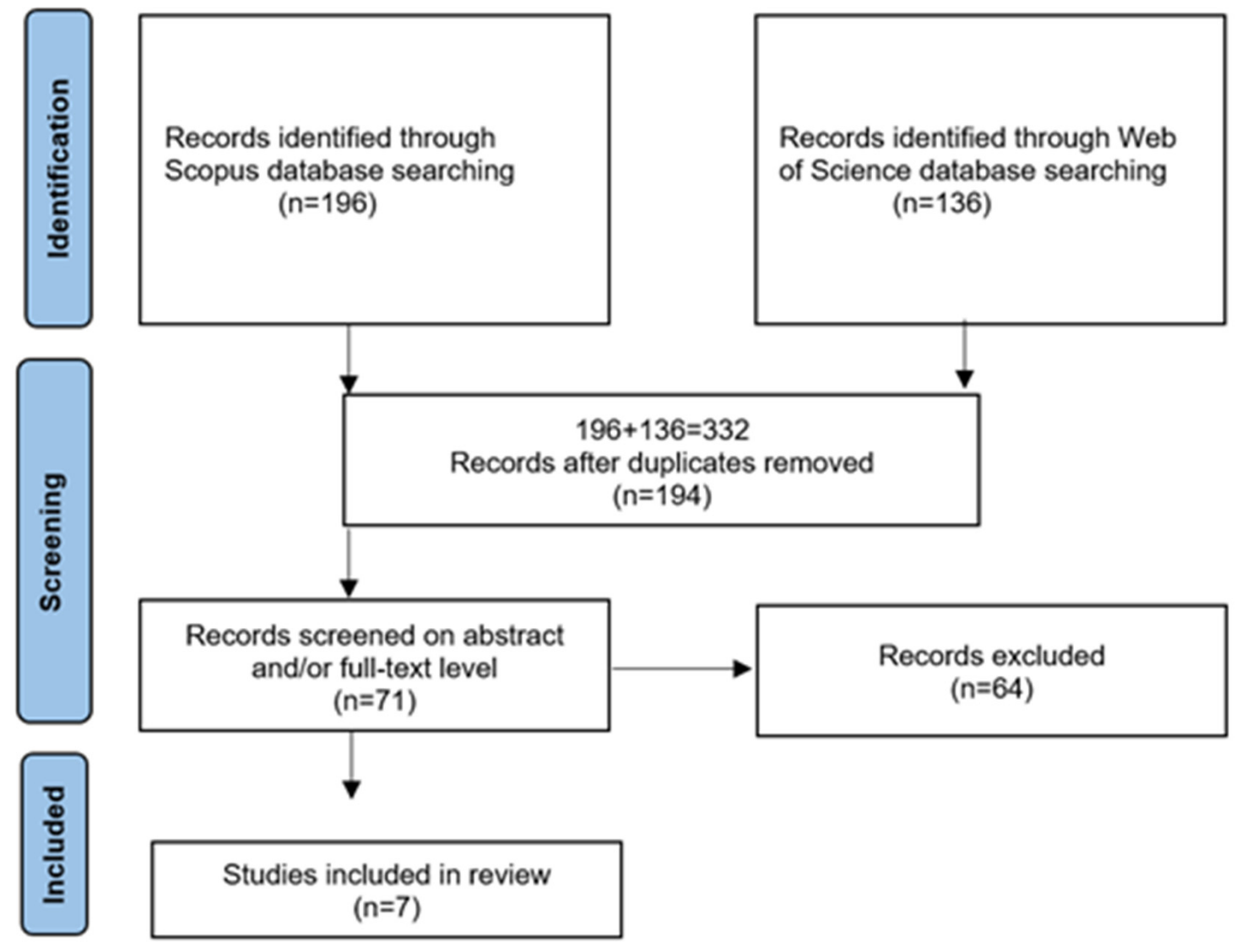

Figure 1. Literature search according to the PRISMA 2020 statement.

Interestingly, currently most of the approaches to identify and define urban challenges are represented by different SC assessment frameworks, that have been developed with the scope to measure the smartness of the cities (smart city initiatives and projects, SC strategy, etc.) but the focus is almost never on mapping the local urban challenges that these SC initiatives and strategies are meant to solve. In case of sustainable urban development (SUD) assessment frameworks, e.g., the Iraqi Urban Sustainability Assessment Framework (IUSAF), the aim is to understand the nature of the local urban sustainability challenges and their importance to relevant stakeholder groups. Therefore, we pointed out three papers that applied urban sustainability indicators in the context of developing countries, as these articles involved an example of how to map local urban challenges impeding sustainable development of the cities. In Iraq, a nation-wide process was conducted in order to develop an Iraqi Urban Sustainability Assessment Framework (IUSAF) and the process was described in two papers $[17,21]$. The process description in a paper by Ameen [17] involved pre-defining urban challenges via literature review relevant to the Iraqi context and then validating the challenges based on the input from expert interviews, followed by a survey among citizens who were asked to rank the priority of the listed challenges from their viewpoint and to add new ones if something was missing from the pre-defined list. Equally important, in the case of the IUSAF, was the evaluation of the ongoing projects already aiming to solve these challenges in one way or another. In case of the roadmap that we propose, there are some similarities. Also, for our approach, it is important not to just identify and define the urban challenges but also to understand them from the viewpoint of the target groups (in our case, it was the local governments but in Iraq they concentrated on the citizen viewpoint). 
Praharaj et al. [19] introduced a bit similar methodology to map urban issues in Indian cities in the context of smart and sustainable city development. Their suggested approach starts with analysing previous studies and identifying typology of factors and then validating and weighing those with relevant stakeholders. Furthermore, Praharaj et al. [19] focused on identifying the common indicators that are able to reflect on the key urban issues relevant to policy makers and the kind that the policy makers are able to "act upon". Praharaj et al. [19] added that, in 2016, the Bureau of Indian Standards (BIS) published smart cities indicators based mostly on the ISO 37120:2014 Sustainable development of communities: Indicators for city services and quality of life and that these smart cities indicators were not considering the local context and the data available. Praharaj et al. [19] suggested an approach that was quite similar to other urban challenge mappings-they started with analyzing previous studies and, based on literature review, identified typology of urban challenge factors, then validated and weighed those factors with relevant stakeholders. Different from our approach, they used that was already existing (as demographic data or data about education, basic infrastructure, etc.). There was no development of methodology for urban challenge data collection; they instead put the available data into the context of smart city indicators and into developing a method for the data analyses from the smart city perspective.

We reached a conclusion that more recent literature, besides Leach et al. [13], also lacks studies where urban challenges are identified in an open process. An increasing number of previous studies aim to address urban challenges, although these urban challenges are usually not defined according to the local context but are assumed to be general for all cities globally. However, global urban challenges like climate change, ageing, and urbanization do not appear in all cities in all countries in a similar manner and importance. Thus, this calls for a need to identify and prioritize also more specific challenges in different cities, regions and countries. To address this research gap, this study introduces a transferable and participatory roadmap for systematically identifying, defining and understanding long-term urban challenges.

\section{Developing a Roadmap for the Identification of Long-Term Urban Challenges}

Having established that there is no existing rigorous and holistic long-term urban challenge diagnostic process, this section explores the conception and design of a roadmap for such a process. In the next section we describe the application of this approach to 35 municipalities in Estonia, which were selected because we wanted to have a strong representation of local governments with urban challenges within one smaller "test" country. In principle, all local governments that can be defined, in a broader sense, as cities or towns, were selected to be a part of the Estonian case study. We started the process of developing an approach that helps to identify and understand long-term urban challenges, by defining the underlying principles that such framework has to take into account. Given our understanding that an accurate identification of urban challenges may result in the design of more targeted smart city initiatives and, therefore, higher chances for smart cities to fulfil their ultimate goals, creating public value and improving citizen quality of life, we decided to embrace the concept of public value to guide the framework design.

Although the current literature is rich in references to public value, this is still an unclear concept that is not being consistently used [22]. In this paper, we adopt Moore's [23] definition, who understands public value to be what public managers aim to produce that not only satisfies the needs of individual citizens but also contributes to collective benefits for society as a whole through various activities and approaches. This definition stresses that public value depends on the particular circumstances in the social contexts and the priorities of a given population [24]. This is actually aligned with our emphasis on the importance of context in shaping urban problems [14], which reveals that cities do not share the same problems, to the same degrees or in the same combinations.

In addition to the public value theory, the framework also builds on the missionoriented approach, which uses specific challenges to stimulate innovation across sectors. 
According to the mission-oriented approach, these are "grand" or terrible challengesmeaning, big, bold, difficult, and complex problems [25], such as climate change and environmental quality, demographic changes, health and well-being, and mobility issues. We argue that these are precisely the types of challenges that cities face nowadays and that these challenges require integrated smart city initiatives and projects across multiple sectors that transcend traditional policy fragmentation. This is also aligned with our definition of a smart city as a city that adopts a global/integral perspective of the city [4].

However, a widely agreed weakness among scholars of the public value theory is the question of how to operationalize it. Driven from the urban challenge perspective, we will couple public value theory with a mission-oriented innovation approach into one conceptual framework where public value theory aims to analyze the outcomes and a mission-oriented innovation approach provides the means for this (see Figure 2). According to this, challenge-driven development in cities should not be a goal itself but should be taken as a tool to create urban public value. Thus, a shift towards evidence of urban value added and outcomes is discussed [26], with an interest, of putting public value theory, initiated by Mark H. Moore, in the center of urban development [27].
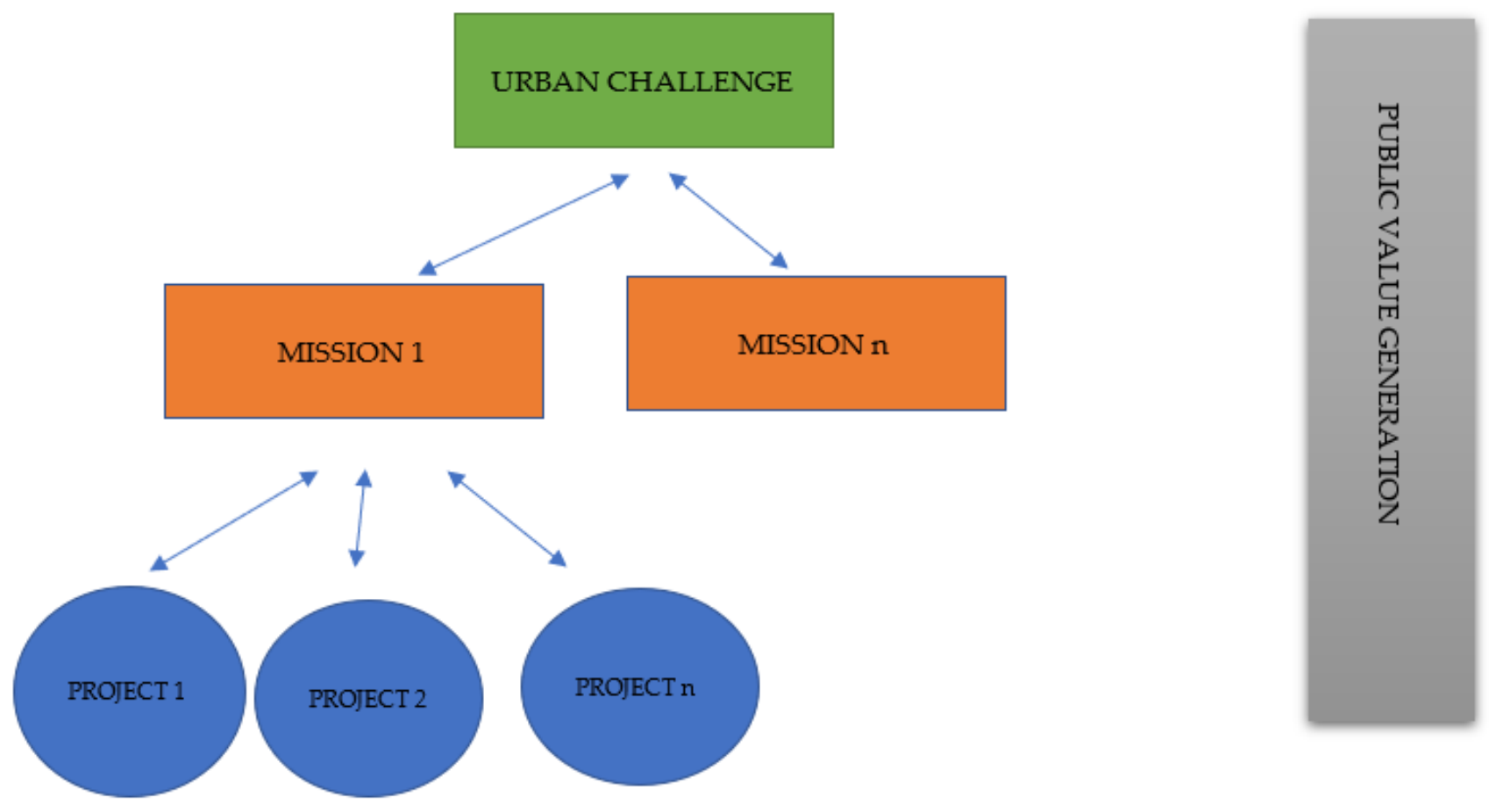

Figure 2. Mission-oriented approach to smart cities. Source: authors edited version of Mazzucato's (2018) concept.

One of the core characteristics of public value is collective consumption based on collective preferences of citizens (versus aggregated individual preferences) independent of who produces it [23]. With regard to mission-oriented innovation policy, according to Mazzucato [25], such policy has an important role in a delivery of smart, inclusive and sustainable growth addressing grand challenges as well as considering changes in mind-set, theories, institutional capabilities and policies (ibid). For example, if a grand challenge is "clean oceans" then a mission can be "A Plastic-free Ocean" (90\% less plastics entering the marine environment and doubling the collection of plastics by 2025) triggered by specific research and innovation (R\&I) projects.

\subsection{Application of the Model}

The roadmap to identify urban challenges was validated with local governments in Estonia. The goal was to include all Estonian local governments that may represent 
urban challenges into the sample. In total, we selected 35 local governments out of 79 , including one mid-size city (the capital, Tallinn, population of 440,000) and three cities with population over 50,000 (Tartu, Narva and Pärnu). The local governments were selected according to two main sampling principles: (1) Is the place labelled as a city (linn, in Estonian), independent of size? (2) Is the place in the capital area, with at least a population of 10,000 residents? According to Eurostat, a city is usually defined as a local administrative unit with the majority of the population living in an urban center, consisting of at least 50,000 inhabitants. However, operationally, the European Commission has put the threshold to 10,000 for Member States with five or less cities above 50,000 when selecting 100 climate-neutral and smart cities [28], which applies to smaller countries. All local governments that met the first criteria of being referred to as a "city" were automatically added to the sample. Local governments that met the second criteria of "population size" within the Capital Area of greater Tallinn (without formally referred to as "city"), were also added to the sample. The full list of local governments with their population is in Appendix A.

The data collection approach was based on mixed methods, a combination of a questionnaire, individual interviews and several workshops with multiple municipalities. Firstly, we developed a questionnaire to map urban challenges in five fields of interest: Energy, Built Environment, Mobility, Data and Governance (see main questionnaire questions in Appendix A). This fields-based approach follows the rather broadly accepted characteristics introduced by Rudolf Giffinger [29] (Smart Governance, Smart Mobility, Smart Environment, Smart Living, Smart Economy and Smart People), adjusted to the local context of Estonia and Finland [30]. The questionnaire was developed by the authors but was also jointly discussed in a questionnaire development webinar in spring 2020 with a broad involvement of researchers. The aim of the questionnaire was to be as simple as possible from the viewpoint of city representatives in order to increase response rates. This questionnaire was carried out in the google forms and was sent to the local governments in collaboration with the Estonian Association of Cities and Municipalities (for the better reach).

\subsubsection{Phase 1: Surveys and Interviews}

In the first phase (see Figure 3), the questionnaire was sent out mid-June with a deadline to respond by August 2020. The answers to the online questionnaire were given by 16 local governments. Authors organized in-depth online interviews with all the representatives that had answered the questionnaire. From cities and local governments who participated in the questionnaires and interviews, seven were represented on a high level - either by the mayor (three cities) or deputy mayors (five cities). The other nine were represented by development specialists or other experts in strategic planning, urban planning and architecture, transport, IT or international projects and communication. Only one mayor (of the City of Sillamäe) was personally involved in responding to the questionnaire and participated in the interview as well. Other two mayors (of Võru and Haapsalu) participated in the interviews, but the questionnaire was filled out by experts. The questionnaires were sent to the general email addresses of the municipalities (e.g., info@city.ee), leaving it to each municipality's own decision who should respond. This is mainly due to the heterogeneous structure of local governments. Thus, the response rate was $45 \%$ (16 out of 35$)$, after several reminders sent to the local governments during the Summer period.

In the next step of Phase 1, all local government contacts that filled in the questionnaire were also asked to participate in a semi-structured online interview with a response rate of $100 \%(16 / 16)$. The questions remained the same but the local government representatives were given an opportunity to explain their written comments and give more detailed responses. In every interview, the respondents of the questionnaire participated as well. The interview served a goal of better understanding the written questionnaire responses. In each interview, at least two representatives from the research team attended-one as an Interviewer and another one as a Note-Taker. In total, four people conducted the 
interviews, with varied roles. Each interview took approximately one hour. The interviews were conducted in Estonian but the notes were translated into English.

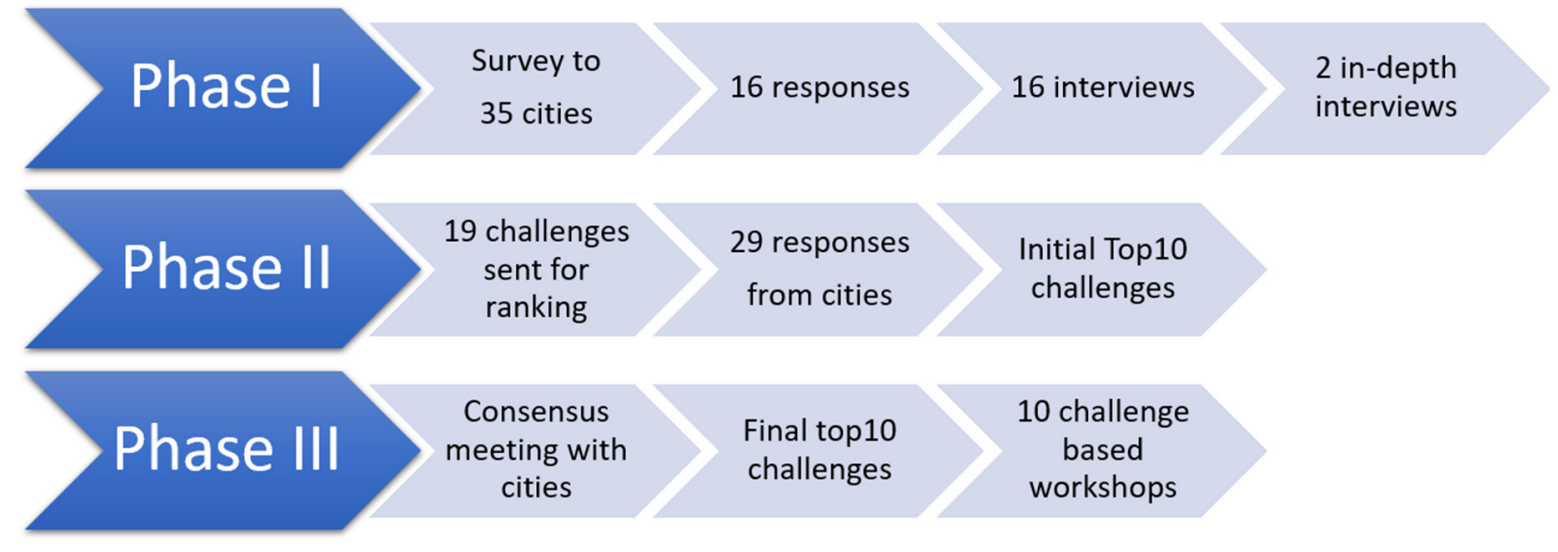

Figure 3. Mapping urban challenges.

In the case of the two bigger cities (Tallinn and Tartu), we conducted also two additional in-depth specialist-level interviews, one online and another one as a face-to-face meeting. The reason for the additional interviews was that during the initial interview there was not enough time to get a thorough overview of their smart city development project portfolios that helped to understand both challenges and research and development capabilities of these cities. In those interviews, some of the smart city projects were discussed in depth, such as an automated vehicles pilot [31] and the smart city focused collaboration project between city government and academia [32].

\subsubsection{Phase 2: Prioritisation of Mutual Challenges}

In the second phase, we grouped individual-local-government-challenges under 19 mutual challenges (as a response to question 1 in the questionnaire, see Appendix A), leaving out individual challenges of local governments. It is important to note that context matters, and different municipalities have different challenges, whereas this process was looking for the challenges that are shared among municipalities, and jointly agreed upon by them. All challenges that were possible to be grouped, and were pointed out by several local authorities, remained in the list, whereas the ones that were specific to one municipality were taken out. These 19 mutual challenges were tagged with one or many thematic fields (Mobility, Energy, Built Environment, Governance and Data).

For validation of this list, these responses were sent back to all (initial sample of 35) participating local governments, independent of whether or not they responded to the questionnaire. In this step, all local governments were asked to rank each urban challenge in the scale of $0-3$ where 0 is not relevant and 3 very relevant. We got feedback from 29 local governments with a response rate of $82 \%(29 / 35)$. If some local government found most of the challenges to be very relevant, then they had a free choice to give 3 points to each challenge (this happened with two cities-Paide and Rakvere). Among two of the largest cities, Tallinn and Tartu, the first city considered 14 out of 19 challenges ( 9 among the top 10) to be very relevant; the second city marked 9 challenges (7 among the top 10) to be very relevant. The third and fourth cities, by population, considered only a few challenges as very relevant-Narva only 2 (both in the final top 10) and Pärnu only one (also among the top 10 challenges). On the downside, there were two small local governments, Saku and Tori, that did not consider any of the top 10 challenges as very relevant. The final top 10 challenges were almost equally divided between five fields in the questionnaire-Energy, Data, Built Environment, Mobility and Governance. Nevertheless, these fields tend to interrelate; for example, the challenges related to Built Environment were twice combined with Energy; and Data related challenges were twice combined with Mobility and twice 
with Governance. The top 10 challenges that were finally selected were ranked according to importance and with indicated field(s):

- The energy consumption of (depreciated) buildings is too high;

- Urban Mobility does not combine the full potential of different modes of transport;

- The energy supply and transport infrastructure for industrial development is low;

- Insufficient and/or uncomfortable public transport;

- Lack of fast and economical connections to other key cities;

- The data to be collected is not available to different user groups;

- Skills and capacity to collect and use data are low;

- Public services are not accessible to all target groups;

- The energy production is too carbon-intensive;

- Urban planning is not comprehensive, optimal and sustainable.

Among the other challenges that did not make it to the top 10 included the following problems: communication channels to relate with residents are not user friendly; traffic planning is not data based; city governance is not transparent enough, lacking clear assessment metrics and not internally focused on delivering services to residents.

\subsubsection{Phase 3: Validation Workshops with Municipalities}

During follow-up workshops with invited local government representatives from the sample of 35 local governments, the top 10 challenges were discussed and, as a result, some changes were collectively made. The workshop members proposed to re-prioritize one challenge from the 12th position into the top 10: "urban planning is not comprehensive, optimal and sustainable". They also decided to merge two of the challenges that were each already in the top 10 but dealing with two sides of the same problem: "energy efficiency of the buildings" (in position 1 after ranking of challenges) and "reconstruction of depreciated buildings" (that was in position 6). The final rankings of top 10 challenges are shown in Figure 4 and the description of these challenges follows in the next section.

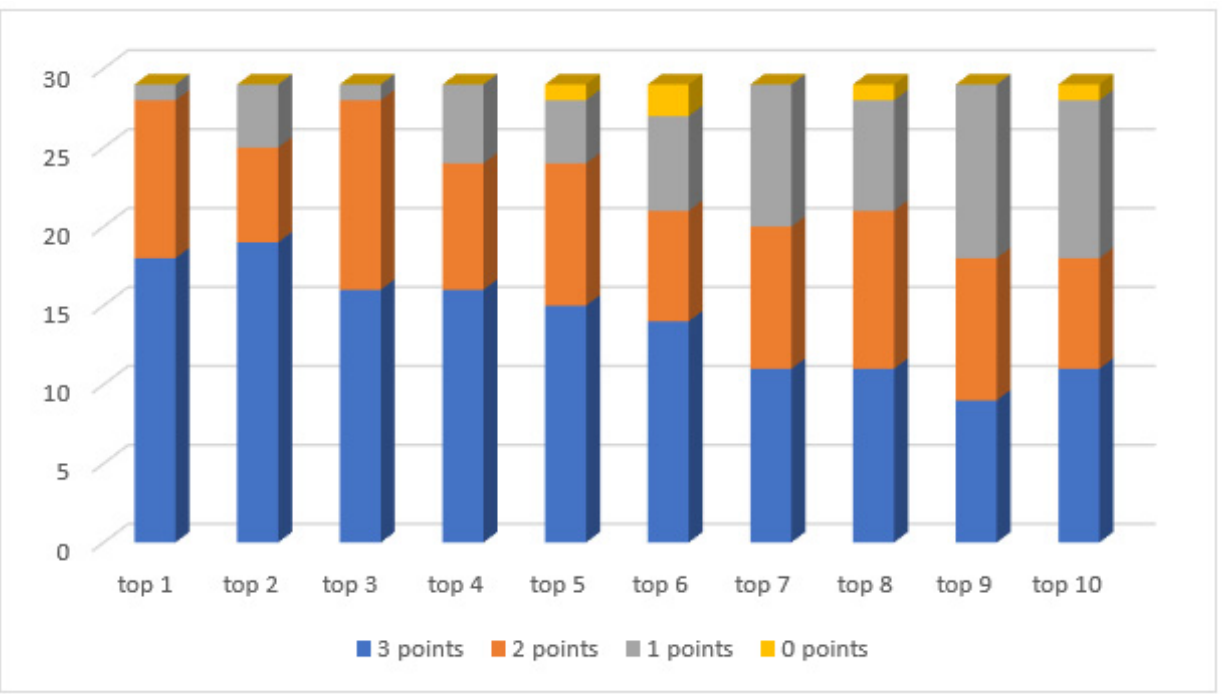

Figure 4. Final Ranking of the top 10 shared challenges by 29 Estonian municipalities.

When the final challenges were selected and validated with local governments, we initiated 10 online workshops to get additional insights to these specific challenges. These workshops, based on one, two, or three challenges at a timebetween urban challenges, leaving out challenges specific to individual cities. This also means harmonizing the context of local governments from one to several. To our knowledge, this is unique, as other studies have been focusing on the global challenges (e.g., urbanization) or ones specific to individual cities (e.g., a particular road needs refinement). 
When designing our approach for systematically identifying, defining, and understanding urban challenges, we combined public value theory and its theoretical framework with a mission-oriented innovation (MOI) approach that provides a larger context of lessons learnt from other mission-oriented innovation portfolio experiences. MOI was helpful in explaining to the local government representatives our goal of mapping urban challenges, Just as for Praharaj et al. [19] for whom it was important to identify the challenges that the local government representatives were able to "act upon", the MOI approach (to define the challenge as pragmatically as possible [33]) was useful for identifying a list of longlasting urban challenges that could be matched with solutions developed within SC-related research. For us, the next step was to combine the pragmatic urban challenges under a common nominator, or a "mission that addresses a societal demand or need" [33], e.g., "Skills and capacity to collect and use data are low" or "Urban planning is not comprehensive, optimal and sustainable".

Following this guideline, we started with collecting input about the urban challenges from all the Estonian local governments in the sample. Received input (questionnaire results and in-depth interviews) was divided into 19 challenges, explained by mission descriptions (concrete problems common to several local governments) and then based on the municipality-ranked feedback, top 10 challenges were systematically selected and agreed upon.

Another important theory for designing our roadmap for identifying nation-wide, long-lasting urban challenges was the public value concept; this allowed us to focus on several municipalities at the same time-which is often neglected in the regional development process, especially in regions with several cities and commuters (e.g., capital areas).

To sum up, the focus of this research was to design an approach for defining urban challenges across multiple cities and to apply this method empirically in Estonia. It was evident, based on the literature review, that there exists a research gap in systematic approaches for analyz ing long-term and common urban challenges. Also, the input asked from the representatives of local governments, in order to define the urban challenges, seemed to be quite scarce.

A roadmap that we propose focuses mostly on understanding and detecting the shared challenges for multiple cities in one region as this will define (at least to some extent) the demand for the research and development agenda and create a shared basis for collaboration between the cities and researchers as well as other relevant stakeholders. The paper contributes to the research about the tools for better identifying, defining and understanding the urban problems and challenges and criticizes the application of the innovative technologies without formeranalyses of the actual public needs and potential contribution to the public value. It was quite evident from the literature review that there is a strong need for a widely applicable systematic approach for identifying, defining and understanding urban challenges.

The main contribution of this paper is a validation of a problem-based approach to smart city solutions that starts with mapping urban challenges in one European country. It is evident that novel urban technologies should deal with actual problems; however, there seems to be a research gap on how to map these urban challenges. Therefore, this article argues that a systematic mapping of urban issues could be considered as a first step when developing more complex smart city solutions. As a follow-up to the current research, we are also considering the mapping of city challenges, using the same process, in other cities in Europe and beyond, and to constantly improve the city challenge mapping process.

Author Contributions: Writing—Original Draft Preparation, R.-M.S. and L.S.; Writing—Review \& Editing, M.G.-H. All authors have read and agreed to the published version of the manuscript.

Funding: This research was funded by two grants: the European Union's Horizon 2020 Research and Innovation Program, under grant agreement No. 856602, and the European Regional Development Fund, co-funded by the Estonian Ministry of Education and Research, under grant agreement No 2014-2020.4.01.20-0289. 
Institutional Review Board Statement: This study did not require a separate approval by the Ethics Board but it does follow Ethics guidelines of authors' institutions.

Informed Consent Statement: Informed consent was obtained from the respondents of the case study for their anonymized information to be published for the research purpose.

Data Availability Statement: Not applicable.

Acknowledgments: The authors would like to thank their colleagues Külle Tärnov and Henry Patzig who participated in data collection.

Conflicts of Interest: The authors declare no conflict of interest.

\section{Appendix A. Sample and Key Questionnaire Questions}

Sample: These local governments (population as of February 2019 [in brackets] according to the Ministry of Finance) were involved in the sample: Tallinn $(438,930)$, Tartu (95,334), Narva (56,459), Pärnu (51,271), Kohtla-Järve (33,709), Viljandi (17,301), Saaremaa (31,453), Saue (22,139), Viimsi $(20,142)$, Rae (18,951), Valga (15,625), Maardu $(15,468)$, Rakvere (15,092), Harku (14,820), Elva (14,583), Jõgeva $(13,523)$, Haapsalu $(13,193)$, Sillamäe $(12,842)$, Lääne-Harju $(12,578)$, Võru $(11,829)$, Tori $(11,699)$, Tartu county $(10,846)$, Paide (10,513), Saku (10,127), Keila (9975), Jõelähtme (6508), Põltsamaa (9756), Lüganuse (8631), Põhja-Sakala (7984), Mulgi (7525), Tõrva (6162), Viru-Nigula (5859), Peipsiääre (5587), Mustvee (5546), Narva-Jõesuu (4601), Loksa (2636).

Key Questionnaire Questions:

Please mention the type of challenges your city will face in the upcoming 5-10 years in relation to:

- Mobility;

- Energy;

- Built Environment;

- Governance;

- Data.

Which digital urban solutions would you like to see in your city in 2025, 2030?

Which strategies is your city following for guiding the trends and working with challenges in the fields of:

- Mobility;

- Energy;

- Built Environment;

- Governance;

- Data.

Which global trends is your city following or using as a broader framework?

- UN Sustainable Development Goals;

- European Green Deal and circular economy;

- Other (which one/which ones);

- None.

Do you have smart city projects initiated (or to be initiated) in your city? If yes, please provide us a brief overview on this. If not, then please explain the reasons for this.

\section{References}

1. Hollands, R.G. Will the real smart city please stand up? Intelligent, progressive or entrepreneurial? City 2008, 12, 303-320. [CrossRef]

2. Papa, R.; Gargiulo, C.; Galderisi, A. Towards an Urban Planners' Perspective on Smart City. J. L. Use Mobil. Environ. 2013, 18, 583-602.

3. Soe, R.M. FINEST Twins: Platform for cross-border smart city solutions. In Proceedings of the 18th Annual International Conference on Digital Government Research, New York, NY, USA, 7-9 June 2017; pp. 352-357.

4. Gascó-Hernandez, M. Building a smart city: Lessons from Barcelona. Commun. ACM 2018, 61, 50-57. [CrossRef] 
5. Silva, B.N.; Khan, M.; Han, K. Towards sustainable smart cities: A review of trends, architectures, components, and open challenges in smart cities. Sustain. Cities Soc. 2018, 38, 697-713. [CrossRef]

6. Monzon, A. Smart Cities Concept and Challenges: Bases for the Assessment of Smart City Projects. In Proceedings of the 2015 International Conference on Smart Cities and Green ICT Systems (SMARTGREENS), Lisbon, Portugal, 20-22 May 2015; pp. 1-11.

7. Riffat, S.; Powell, R.; Aydin, D. Future cities and environmental sustainability. Futur. Cities Environ. 2016, 2, 1. [CrossRef]

8. Derrible, S. Complexity in future cities: The rise of networked infrastructure. Int. J. Urban Sci. 2017, 21, 68-86. [CrossRef]

9. Martinez-Fernandez, C.; Audirac, I.; Fol, S.; Cunningham-Sabot, E. Shrinking Cities: Urban Challenges of Globalization. Int. J. Urban Reg. Res. 2012, 36, 213-225. [CrossRef]

10. Anthopoulos, L.; Janssen, M.; Weerakkody, V. Comparing Smart Cities with Different Modeling Approaches. In Proceedings of the WWW 2015 Companion; ACM: Florence, Italy, 2015.

11. Fernandez-Anez, V.; Fernández-Güell, J.M.; Giffinger, R. Smart City implementation and discourses: An integrated conceptual model. The case of Vienna. Cities 2018, 78, 4-16. [CrossRef]

12. Nijkamp, P.; Cohen-Blankshtain, G. The importance of ICT for cities: E-governance and cyber perceptions. In Metropolitan Regions: Knowledge Infrastructures of the Global Economy; Klaesson, J., Johansson, B., Karlsson, C., Eds.; Springer: Berlin/Heidelberg, Germany, 2013; Volume 72, pp. 295-308.

13. Leach, J.M.; Mulhall, R.A.; Rogers, C.D.F.; Bryson, J.R. Reading cities: Developing an urban diagnostics approach for identifying integrated urban problems with application to the city of Birmingham, UK. Cities 2019, 86, 136-144. [CrossRef]

14. Nam, T.; Pardo, T.A. Smart city as urban innovation: Focusing on management, policy, and context. In Proceedings of the 5th International Conference on Theory and Practice of Electronic Governance, Tallinn, Estonia, 29-28 September 2011; pp. 185-194.

15. Weeks, J.R. Defining Urban Areas. In Remote Sensing of Urban and Suburban Areas. Remote Sensing and Digital Image Processing; Rashed, T., Jürgens, C., Eds.; Springer: Dordrecht, The Netherlands, 2010.

16. Kropf, K. The Handbook of Urban Morphology; Wiley: London, UK, 2018; ISBN 978-1-118-74769-8.

17. Ameen, R.F.M. Evaluation of the sustainability of the urban development sector in Iraq. IOP Conf. Ser. Mater. Sci. Eng. 2021, 1067, 012064. [CrossRef]

18. Frantzeskaki, N. Seven lessons for planning nature-based solutions in cities. Environ. Sci. Policy 2019, 93, 101-111. [CrossRef]

19. Praharaj, S.; Han, J.H.; Hawken, S. Towards the right model of smart city governance in India. Int. J. Sustain. Dev. Plan. 2018, 13, 171-186. [CrossRef]

20. van Winden, W.; Carvalho, L. Intermediation in public procurement of innovation: How Amsterdam's startup-in-residence programme connects startups to urban challenges. Res. Policy 2019, 48, 103789. [CrossRef]

21. Mohsin, M.M.; Beach, T.; Kwan, A. Public perceptions of urban sustainable challenges in developing countries. WIT Trans. Ecol. Environ. 2017, 226, 131-140.

22. Alford, J.; Hughes, O. Public value pragmatism as the next phase of public management. Am. Rev. Public Adm. 2008, 38, 130-148. [CrossRef]

23. Moore, M.H. Creating Public Value: Strategic Management in Government; Harvard University Press: Cambridge, MA, USA, 1995.

24. O'Flynn, J. From new public management to public value: Paradigmatic change and managerial implications. Aust. J. Public Adm. 2007, 66, 353-366. [CrossRef]

25. Mazzucato, M. Mission-oriented innovation policies: Challenges and opportunities. Ind. Corp. Chang. 2018, $27,803-815$. [CrossRef]

26. Caird, S.P.; Hallett, S.H. Towards evaluation design for smart city development. J. Urban Des. 2019, 24, 188-209. [CrossRef]

27. Soe, R.M. Innovation Procurement as Key to Cross-border ITS Pilots. Int. J. Electron. Gov. 2020, $12,1$.

28. European Commission. Proposed Mission: 100 Climate-Neutral Cities by 2030-by and for the Citizens. 2020. Available online: https:/ / ec.europa.eu/info/publications/100-climate-neutral-cities-2030-and-citizens_en (accessed on 14 December 2021).

29. Giffinger, R. Smart Cities: Ranking of European Mid-Sized Cities. 2007. Available online: http://www.smart-cities.eu/download/ smart_cities_final_report.pdf (accessed on 14 December 2021).

30. Soe, R.-M. Smart Twin Cities via Urban Operating System. In Proceedings of the ICEGOV'17, New Delhi, India, 7-9 March 2017; pp. 391-400.

31. Soe, R.M.; Müür, J. Mobility acceptance factors of an automated shuttle bus last-mile service. Sustainability 2020, $12,5469$. [CrossRef]

32. Sarv, L.; Kibus, K.; Soe, R.M. Smart city collaboration model: A case study of university-city collaboration. In Proceedings of the 13th International Conference on Theory and Practice of Electronic Governance, Athens, Greece, 23-25 September 2020; pp. 674-677.

33. Mazzucato, M.; Penna, C. The Brazilian Innovation System: A Mission-Oriented Policy Proposal. 2016. Available online: http://sro.sussex.ac.uk/id/eprint/61974/ (accessed on 14 December 2021). 